\title{
A POSSIBLE NEW MODEL OF MICROSCOPIC VISCOSITY OF METALS FOR NANO-HOLE FILLING
}

\author{
Zoltán Farkas, Antal Ürmös* \\ Institute of Microelectronics and Technology, Óbuda University, 1084 Tavaszmező utca 15-17, Budapest, \\ Hungary \\ https://doi.org/10.47833/2020.2.ENG.002
}

\section{Keywords: \\ gallium arsenide \\ nanostructure \\ nanohole \\ inverted quantum dot \\ droplet epitaxy \\ surface processes}

\section{Article history:}

Received 27 Jan 2020

Revised 20 Feb 2020

Accepted 10 Apr 2020

\begin{abstract}
The advantage of application of different nanostructures is that on one hand new semiconductor devices can be fabricated and on the other hand parameters of currently used devices can be improved as well. An example of the latter is the group of so called inverted quantum dots. The relevant burying process can be simulated by multiple methods. One of this methods is taking into consideration the microscopic viscosity of melted metals. The burying process was described by an empiric model in case of gallium and indium metals in a previous research paper of ours. A possible new interpretation of microscopic viscosity was also scratched in that paper. This new model will be detailed in the present paper.
\end{abstract}

\section{Introduction}

The advantage of application of different nanostructures is that new semiconductor devices can be fabricated (eg. quantum dot (QD) cell automates [1][2]) or the parameters of currently used devices can be improved significantly (as in the case of high efficiency solar cells [3][4]). These devices can be fabricated in divers ways, for example with droplet epitaxy [5][6][7], which is a type of molecular beam epitaxy [8][9] [10] [11].

One of these nanostructures is the group of so-called inverted quantum dots [12]. These structures cab be prepared by droplet epitaxy mentioned above [13]. The idea of droplet epitaxy was developed by Koguchi and his associates in the beginning of '90's [14]. The essence of this technology is that first a metallic droplet of the third group (eg. Gallium) is deposited onto the GaAs carrier. Afterwards a nanostructure is formed. The type of this nanostructure is a function of several factors: the temperature of the sample, Arsenic background pressure, Gallium flux, annealing time and temperature (Fig 1) [15].

As it can be seen on (Figure 1) nanoholes are formed at high temperature and minimal As background pressure [12] [16]. This happens according to the process detailed below. A Ga droplet is deposited onto the GaAs substrate. As atoms diffuse into the droplet from the substrate due to the gradient of concentration. Arsenic atoms desorb from the surface of the droplet, meanwhile Gallium atoms leave the droplet via surface diffusion. Finally, a nanohole is formed. 


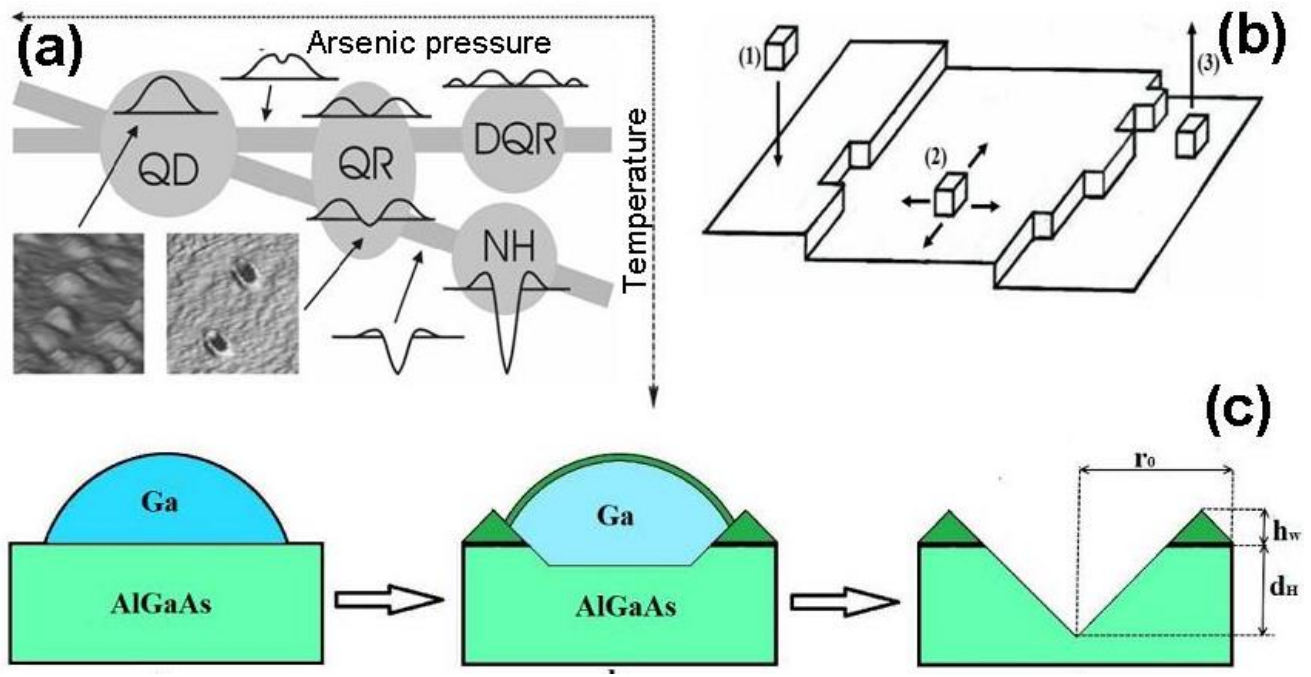

Figure 1. (a) The types of evolving nanostructures as function of Arsenic pressure and temperature of the carrier (source: [15]); (b) Surficial physical processes. (1) adsorption, (2) surficial diffusion, (3) desorption (source [16]); (c) Phases of nanohole formation (source [16])

$r_{0}$ denotes the outer radius (of the ring around the nanohole), $h_{w}$ is the height of ring, $d_{H}$ is the depth of nanohole. If the nanohole is buried with metallic (eg. Ga) atoms an inverted quantum dot is formed. There are four types of inverted quantum dots: those belonging to type 1 are white light emitters, those of type 2 are partially filled inverted quantum dots, those of type 3 are ultra-low density quantum dots, and those of type 4 are vertically stacked quantum dot molecules [16]. There are multiple ways to simulate the burying process, eg. Kinetic Monte Carlo algorithm at atomic level [17] or taking into consideration the microscopic viscosity of the melted metal [18] [19].

The dynamic viscosity is a factor depending on the quality of the fluid that connects shear stress to velocity of deformation.

$$
\tau=\mu * \frac{d \gamma}{d t},
$$

where $\tau$ is the shearing stress, $\mu$ is the dynamic viscosity, $d \gamma / d t$ is the velocity of deformtion. This type of viscosity can be determined according to multiple ways in case of liquid metals. Now the Arrhenius-Andrande equation will be used [20] as shown below:

$$
\mu(T)=\mu_{0} * e^{\frac{E_{0}}{R * T}} .
$$

$\mu(T)$ is the dynamic viscosity as a function of temperature, $T$ is the temperature in Kelvins, $\mu_{0}$ is a pre-exponential factor ( 0.436 for Gallium), $E_{0}$ is the bulk cohesion energy (it is $271 \mathrm{~kJ} / \mathrm{mol}$ for Gallium) [21], $\mathrm{R}$ is the universal gas constant $(8,3144 \mathrm{~J} / \mathrm{K} * \mathrm{~mol})$.

The latter method was used in our previous research [18][19][22]. The burying of the hole was described with an empiric model for metals Gallium and Indium in the corresponding papers of ours and briefliy outlined a possible new theoretical model of microscopic viscosity. We detail this model in the present paper.

\section{The new theoretical model}

The atoms that arrive from the atomic source (Knudsen cell) condensate on the surface where multiple physical processes may take place. The processes can be divided into three major groups: (1) adsorption, (2) surficial diffusion, (3) desorption. The processes compete with each other at the same time during crystal growth (Figure $1 / \mathrm{b}$ ).

This layer growing process can be modelled by continuous and by discrete models. [23]. One kind of discrete models is the Kinetic Monte-Carlo algorithm. We start with this 
algorithm to explain the possible new model of microscopic viscosity. Let us define the probability of the occurance of an event at atomic level. [17] [24]:

$$
P\left(E_{a}, T\right)=e^{-\frac{E_{a}}{R * T}},
$$

where $E_{a}$ is the activation energy of the given event, $T$ is the temperature in Kelvins, $R$ is the universal gas constant $(8,3144 \mathrm{~J} / \mathrm{mol} * K)$. With this formula one can define the freqence of change of location:

$$
k=k_{0} e^{-\frac{E_{a}}{R * T}},
$$

where a $k_{0}$ is the energy of atomic vibration. It can be determined as:

$$
k_{0}=\frac{2 * T * k_{B}}{h},
$$

where $k_{B}$ is the Boltzmann constant, $h$ is the Planck constant. Let us define the $\rho=\rho\left(E_{a}, T\right)$ geometric factor as:

$$
\rho\left(E_{a}, T\right)=l * e^{\frac{2 * E_{a}}{R * T}},
$$

where $l$ is a free parameter that can be scalar or function of either one or multiple variables. Consequently, the formula of microscopic dynamic viscosity is:

$$
\mu\left(E_{a}, T\right)=k * \rho\left(E_{a}, T\right)=k_{0} * e^{-\frac{E_{a}}{R * T}} * l * e^{\frac{2 * E_{a}}{R * T}}=k_{0} * l * e^{\frac{E_{a}}{R * T}},
$$

where $k_{0} * l$ product is the microscopic pre-exponential factor. Let $E_{a}$ activation energy be equal to the bonding energy of atoms $\left(E_{\text {bond }}\right)$. Furthermore let us suppose that the surface is absolutely smooth in starting condition in other words the process starts with a surface free of atomic clusters. Let us introduce $E_{p}$ which is the cohesion energy of the nanoparticle supposing that nanoparticle is ball shaped [25]. In this case the bonding energy of the atoms and cohesion energy of the nanoparticle are related in the formula below:

$$
E_{p}=\frac{1}{2} * \frac{R^{3}}{r^{3}} * \beta * E_{\text {bond }} *\left(1-3 * \frac{r}{R}\right),
$$

where $R$ is the radius of the nanoparticle, $r$ is the radius of the atom, $\beta$ is the number of atomic bondings. The melting temperature of the nanoparticle is as follows:

$$
T_{p}=\frac{0,0032}{k_{B}} * \frac{1}{2} * \frac{R^{3}}{r^{3}} * \beta * E_{\text {bond }} *\left(1-3 * \frac{r}{R}\right),
$$

where $k_{B}$ is the Boltzmann constant. Thus a possible new formula of microscopic viscosity is:

$$
\mu\left(E_{p}, T\right)=k_{0} * l * e^{\frac{E_{p}}{R * T}}
$$

\section{Discussion}

In this section it will be discussed that what is the relationship between the theoretical model described above and a monoexponential empirical model in case of indium and gallium. It follows that $l$ free parameter can be defined as:

$$
l=\frac{a}{k_{0}}=\frac{a * h}{2 * k_{B} * T}
$$

according to formula (10) where $a$ is the basic term of exponential function.

In case of Gallium the bonding energy is $6.27507 \mathrm{e}+15 \mathrm{~J}$, the radius of an atom is $136 \mathrm{pm}$. On Figure 2 an empirical model is sketched the formula of which is:

$$
\mu\left(E_{p}, T\right)=7,533 * e^{-0,003907 * x},
$$


where $x$ is the negative reciprocal of the temperature $\left(x=-\frac{1}{T}\right)$.

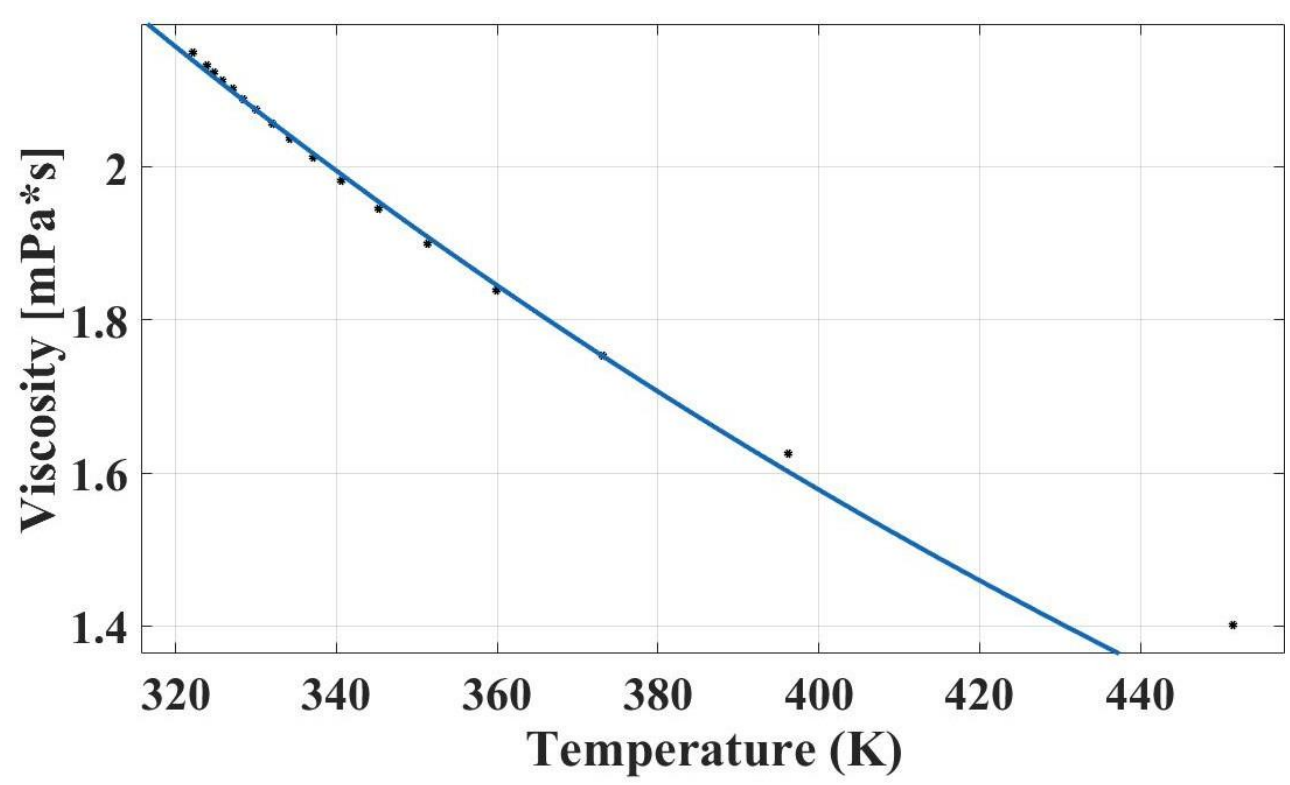

Figure 2. Microscopic viscosity of Gallium as a function of the temperature. A monoexponential empirical approximation

In equation (10) in the exponent of exponential term the value of $E_{p}$ cohesion energy is $0.0324843608 \mathrm{~J}$. After reformulating and solving the equation (8) it is obtained that there are 27 Gallium atoms in the nanoparticle. The base term is $k_{0} * l=7,533$. It follows that in case of Gallium the value of factor $l$ is:

$$
l=\frac{1.8077 * 10^{-10}}{T} .
$$

as a function of the temperature.

In case of Indium the bonding energy is $1.033362 \mathrm{e}+16 \mathrm{~J}$, the radius of an atom $155 \mathrm{pm}$. On Figure 3 a monoexponential empirical model is shown:

$$
\mu\left(E_{p}, T\right)=9,438 * e^{-0,003396 * x},
$$

where $x$ is the negative reciprocal of the temperature $\left(x=-\frac{1}{T}\right)$. 


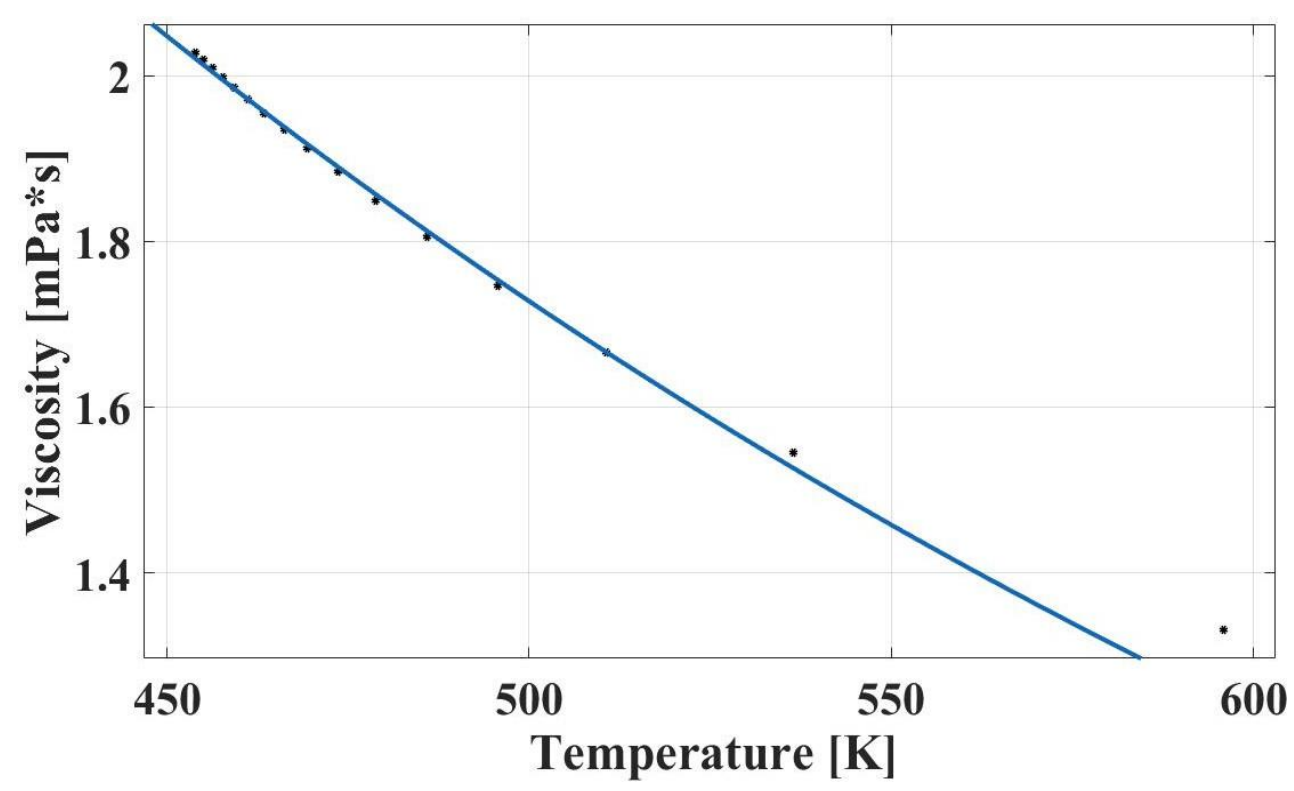

Figure 3. Microscopic viscosity of Indium as a function of the temperature. A monoexponential empirical model.

In equation (10) in the exponent of exponential term the value of $E_{p}$ cohesion energy is $0.0282357024 \mathrm{~J}$. Rearranging equation (8) yields that the nanoparticle contains $27 \mathrm{In}$ atoms. The base term is $k_{0} * l=9,438$. Subsequently factor $l$ is:

$$
l=\frac{2.2648 * 10^{-10}}{T} \text {. }
$$

as a function of temperature.

\section{Conclusion}

Either new semiconductor devices can be fabricated or parameters of currently used devices can be improved with nanostructures. These nanostructures can be manufactured by droplet epitaxy which is a type of molecular beam epitaxy (MBE). The so called inverted quantum dots belong to this kind of nanostructures. This kind of nanostructures are fabricated as follows. A nanohole is prepared and is buried thereafter. The burying process can be simulated in multiple ways. One possible method is taking into consideration the microscopic viscosity of molten metals. In this paper the new model of the dynamic viscosity of molten metals is detailed. This new model was compared to a former empirical model of ours. This two models can be correlated.

\section{References}

[1] G.L. Snider, A.O. Orlov, I. Amlani, X. Zuo, G.H. Bernstein, C.S. Lent, J.L. Merz and W. Porod, "Quantum Cellular Automata," Journal of Vacuum Science \& Technology A: Vacuum, Surfaces, and Films, vol. 17, pp. 1394-1398, 1999.

[2] G.L. Snider, A.O. Orlov, I. Amlani, X. Zuo, G.H. Bernstein, C.S. Lent, J.L. Merz and W. Porod, "Quantum-dot cellular automata: Review and recent experiments (invited)," Journal of Applied Physics, vol. 85, pp. 4283-4285, 1999.

[3] A. Luque, A. Martí, C. Stanley, "Understanding intermediate-band solar cells," Nature Photonics, vol. 6, pp. 146152, February 2012.

[4] K. E. Jasim, "Quantum Dots Solar Cells," in Solar Cells - New Approaches and Reviews.: InTech, 2015, ch. 11, pp. 303-331.

[5] Nemcsics Akos, Urmos Antal, Toth Lajos, "Droplet Epitaxy and its Possibilities in Nano-electronics," in IEEE, vol. International Symposium on Next-Generation Electronics (ISNE 2018), Taipei, Taiwan, 2018, pp. 122-124.

[6] Ákos Nemcsics, "Droplet Epitaxy as a Tool for the QD-Based Circuit Realization," in Nonmagnetic and Magnetic Quantum Dots, Vasilios N. Stavrou, Ed. London, United Kingdom: IntechOpen, 2017, ch. 3, pp. 43-59.

[7] Ákos Nemcsics, "Quantum Dots Prepared by Droplet Epitaxial Method," in Quantum Dots - Theory and Applications, Vasilios N. Stavrou, Ed. London, United Kingdom: IntechOpen, 2015, ch. 5, pp. 120-149. 
[8] M. A. Herman, H. Sitter, Molecular Beam Epitaxy, Fundamentals and Current Status 2nd. ed. Berlin: Springer, 1996.

[9] [9] P. Frigeri, L. Seravalli, G. Trevisi G, S. Franchi, "Molecular Beam Epitaxy: An Overview," in Comprehensive Semiconductor Science and Technology, 3, F. Roberto, K. Hiroshi B. Pallab, Ed. Amsterdam, Netherland, 2011, pp. 480-522.

[10] H. Mohamed, Ed., Molecular Beam Epitaxy: From Research to Mass Production.: Elsevier Science, 2012.

[11] Nemcsics Á., Réti I., Tényi V. G., Kucsera P., Tóth L., Harmat P., Mieville A., Csutorás M., Kupás-Deák B., Sándor T., Bozsik J., "Technical conditions of the nanostructures, produced by Molecular Beam Epitaxy" GÉP LXI., p. 29, 2010. (in Hungarian)

[12] Á. Nemcsics, B. Pődör, L. Tóth, J. Balázs, L. Dobos, J. Makai, M. Csutorás, A. Ürmös, "Investigation of MBE grown inverted GaAs quantum dots," Microelectronics Reliability, vol. 59, pp. 60-63, 2016.

[13] Á, Nemcsics; A, Ürmös, "Subject of "Low-dimensional Selfassembling System" in the mechatronical education at the Obuda University," in Subotica Technical College of Applied Sciences, vol. Proceedings of the 3rd international conference and workshop Mechatronics in Practice and Education - MECHEDU 2015, Szabadka, Szerbia, 2015, pp. 92-95.

[14] N. Koguchi, S. Takahashi, T. Chikyow, "New MBE growth method for InSb quantum well boxes," Journal of Crystal Growth, pp. 688-692, 1991.

[15] Á. Nemcsics, "Growth of GaAs and related materials based nano-structures by droplet epitaxial method," Recent Res. Devel. Mat. Sci. Engg., vol. 4, pp. 53-87, 2011.

[16] C. Heyn, D. Sonnenberg, and W. Hansen, "Local Droplet Etching: Self-assembled Nanoholes for Quantum Dots and Nanopillars," in Nanodroplets. New York: Springer Science, 2013, pp. 363-383.

[17] W. Miller, "Simulation of Epitaxial Growth by Means of Density Functional Theory, Kinetic Monte Carlo, and Phase Field Methods," in Handbook of Crystal Growth: Fundamentals (Volume I., Part A: Thermodynamics and Kinetics), 2nd ed. New York: Elsevier B.V, 2015, pp. 521-559.

[18] Antal Ürmös, Zoltán Farkas, Ákos Nemcsics, "Contribution to the understanding of III-V based nanohole filling," American Journal of Condensed Matter Physics, vol. 2, pp. 50-56, 2017.

[19] Antal Ürmös, Zoltán Farkas, Ákos Nemcsics, "Modeling of III-V-based Nanohole Filling," Acta Polytechnica Hungarica, vol. 17, no. 2, pp. 91-111, 2017.

[20] W. F. Gale, T. C. Totemeier, "General physical properties," in Smithells Metals Reference Book (Eighth Edition).: Elsevier Inc., 2004, pp. 1-45.

[21] Charles Kittel, Introduction to Solid State Physics, 8th ed.: John Wiley and Sons, 2005.

[22] Ürmös Antal, Farkas Zoltán, Nemcsics Ákos, "Modelling of the filling of the GaAs-based nanoholes" in Kandó Kálmán Villamosmérnöki Kar, Budapest, Magyarország, 2016, pp. 1-19. (in Hungarian)

[23] H. E. Stanley A. L. Barabási, "Basic phenomena of MBE," in Fractal Concepts In Surface Growth. Cambridge: Cambridge University Press, 1995, ch. 12, pp. 128-230.

[24] L. Nurminen, A. Kuronen, K. Kaski, "Kinetic Monte Carlo simulation of nucleation on patterned substrates," Phys. Rev. B, vol. 63, no. 3, p. 035407, December 2000.

[25] W.H. Qi, M.P. Wang, "Size and shape dependent melting temperature of metallic nanoparticles," Materials Chemistry and Physics, vol. 88, no. 2-3, pp. 280-284, 2004.

[26] Derek W. Smith, Inorganic Substances: A Prelude to the Study of Descriptive Inorganic Chemistry, 1st ed. Cambridge, United Kingdom: Cambridge University Press, 1990, vol. Cambridge Texts in Chemistry and Biochemistry. 